\title{
The Relationship between Spousal Age Difference and Violence Against Wife in Nigeria: A Generalized Linear Modelling Approach
}

\author{
ANTHONY C. AKPANTA, IDIKA E. OKORIE, FAITH KANU \\ Department of Statistics, Faculty of Biological and Physical Sciences, Abia State University, \\ Uturu. P.M.B 2000 Uturu, Nigeria \\ Email: ac.akpanta@abiastateuniversity.edu.ng; idikaeke@ymail.com; kanu.faith@yahoo.com
}

\begin{abstract}
The act of violence against wife is condemnable and attracts various legal penalties, globally. This article attempts to find a link between spousal age difference and violence (Emotional, Physical and Sexual) against wives in Nigeria. The result show that wives who are older than their partners are more likely to experience sexual and emotional violence; also, wives who are same age as their husbands are more likely to experience sexual violence; whereas wives who are 1-4 years younger than their husbands are more likely to experience physical violence; while wives 5 years or more younger than their husbands are generally less likely to experience any form of violence.
\end{abstract}

Keywords: Spousal Age difference, Violence against Wife, Categorical Data, Generalized Linear Model and Probabilities.

\section{INTRODUCTION}

All over the world, violence against women have continued to assume unprecedented proportion, for instance, according to Essel [1] who reported that global statistics show that the probability that a woman will experience some form of physical or sexual violence in her lifetime is 0.6 , and she went on to mention the result due to the research of Gender Studies and Human Rights Documentation Centre 1998 in Ghana, which found that 1 in 3 women suffered physical violence, $27 \%$ of women had been sexually abused and $5 \%$ of women had been circumcised. She also quoted the sobering statistics from the Domestic Violence and Victim Support Unit (DOVVSU) Ghana 2010 report which was equally worrisome and revealed that Ghana recorded a total of 986 defilement cases which increased to 1176 in 2011 . Worse still in 2012, 10 spousal murders, the majority being husbands killing wives, were recorded in the same country.

Despite concerted efforts to eradicate this ugly phenomenon by both government and nongovernmental agencies' violence against women is still with us unabated. In both the developed and undeveloped countries of the world the story is the same. For instance, Bowman [2], recent review states that in search for reasons why men batter and kill their wives an American historian David Peterson del Mar concludes that since 1960s men have become more ambivalent toward women, and more anxious about their own roles. The result has been more violence against wives by some husbands. In terms of class, he discovered that violence against wives cut across social divisions. He concluded his work by suggesting possible ways to end wife-beating, one of which being that the attitude of family and friends who treat violence as a private affair must end.

In a similar study, Amoakohene [3] examined violence against women in Ghana, its effect and the perception and views of Ghanaian women. The violence experienced by Ghanaian women in different age groups, profession, and socio-economic status were examined. She defined domestic violence as a deliberate violence by husbands (male partners). According to her, domestic violence against women is multifaceted: sexual, socio-economic, cultural, pseudoreligious and mental torture. Opinions of Ghanaian women on their perception towards this 
ugly trend were sampled from two major cities in Ghana: Accra and Kumasi. Lastly, the study looked at the effects of domestic violence on Ghanaian women's health and overall well-being and concludes with suggestions for addressing this social menace.

In related development Ellsberg et al. [4] in their article, carried out a study and compared the results on violence against women in three populations in Nicaragua. The scopes of two of the studies were regional: Leon and Managua and aimed at women's experiences of violence, while the other study was a Demographic Health Survey (DHS). The estimated prevalence of women under physical violence by their partner was significantly higher in Leon with $52 \%$ and Managua with $69 \%$, compared with $28 \%$ that was obtained for DHS. Moreover, the authors used pooled multivariate logistic regression analysis to explain the observed differences.

The consequences of violence against women have been so dreadful not only because of its adverse effects on the women in question but also due to its negative influence on the nation's social, economic and human development. And this calls for a serious concern. For instance, according to Krantz and Garcia-Moreno [5], violence against women is currently well-known to be a public health problem and human rights violation of global significance.

Jensen and Thornton [6], in their article which considered four selected countries (Benin Republic, Colombia, India and Turkey), noted that women who marry younger are also more likely to marry much older men as indicated by the husband-wife age gap. The trend is most salient in Benin Republic where women who marry under the age of 15 marry men who are on average 11.1 years older than them. In contrast, women who delay marriage until after they are 30 have an average husband-wife age gap of 4.9 years. The other countries show a similar trend of a declining husband-wife age gap as women's age at marriage increases. Interestingly, the paper explained that this age differences between husband and wife can affect the power, status and autonomy of women even including physical safety within the household. Older men or their mothers and families, may be able to manipulate or exert control over younger women to a greater extent than in marriages with no such age difference. They also found that women who marry very early are more likely to experience domestic violence.

However, according to the Nigeria Demographic and Health Survey (NDHS), 2013 [7] there is no clear pattern between spousal violence and spousal age difference in Nigeria. It is therefore to these ends that we give a clear paradigm of this anti-social behaviour of husband/partner against wife/partner by using the 2013 NDHS, 2013 [7] data on violence against wife in Nigeria to make similar findings as in Jensen and Thornton [6].

The generalized linear model would be used as a reasonable statistical instrument to connect each domestic violence (emotional violence, physical violence and sexual violence) to the husband-wife age difference with corresponding levels of probabilities. Extensive literature on the generalized linear modeling could be found in [8] and [9].

The remainder of this paper contain: Section 2 which introduces the method of analysis and data, Section 3 which present the results and discussions and Section 4 which gives the conclusion of the study.

\section{METHODS}

Suppose we classify a random sample of $n$ subjects according to two characteristics A and B, e.g. age categories of married women in relation to their husband's age and various types of violence against them by their husbands. Let $y_{i j}$ be the number of subjects that fall into category $i$ of A and $j$ of $\mathrm{B}, i=1, \cdots, I, j=1, \cdots, J$. Obviously $\sum_{i j} y_{i j}=n$.

The data $\left\{y_{i j}\right\}$ from a two-dimensional (2-D) contingency table.

Table 1. 2-D Contingency Table

\begin{tabular}{|c|c|c|c|c|c|}
\hline & \multicolumn{4}{|c|}{ B } & \multirow[b]{2}{*}{ Total } \\
\hline A & $B_{1}$ & $B_{2}$ & $\ldots$ & $B_{I}$ & \\
\hline$A_{1}$ & $y_{11}$ & $y_{12}$ & $\ldots$ & $y_{1 J}$ & $y_{1 .}$ \\
\hline$A_{2}$ & $y_{21}$ & $y_{22}$ & $\ldots$ & $y_{2 J}$ & $y_{2 .}$ \\
\hline$\vdots$ & $\vdots$ & $\vdots$ & $\ldots$ & $\vdots$ & $\vdots$ \\
\hline$A_{I}$ & $y_{I 1}$ & $y_{I 2}$ & $\cdots$ & $y_{I J}$ & $y_{I .}$ \\
\hline Total & $y_{.1}$ & $y_{.2}$ & $\ldots$ & $y_{. J}$ & $y=n$ \\
\hline
\end{tabular}


where the column total $y_{. J}=\sum_{j=1}^{I} y_{i j}$, row total $y_{i .}=\sum_{i=1}^{J} y_{i j}, i=1, \cdots, I, j=1, \cdots, J$. The grand total is $y_{. .}=\sum_{i=1}^{I} \sum_{j=1}^{J} y_{i j}=n$.

The distribution of $\left\{y_{i j}\right\}$ is multinomial:

$$
P\left(Y_{11}=y_{11}, \cdots, Y_{I J}=y_{I J}\right)=\frac{n !}{y_{11} ! \cdots y_{I J} !} \pi_{11}^{y_{11}} \cdots \pi_{I J}^{y_{I J}}
$$

where $y_{11}, \cdots, y_{I J} \geq 0, y_{11}+\cdots+y_{I J}=n$ and $\pi_{i j}$ are cell probabilities. For example, $\pi_{11}$ is the probability that a randomly selected subject falls into row 1 and column 1 . The marginal probabilities are $\pi_{i .}=\sum_{j} \pi_{i j}$ and $\pi_{. j}=\sum_{i} \pi_{i j}, i=1, \cdots, I, j=1, \cdots, J$.

To test the hypothesis of independence (no association) between A and $\mathrm{B}$, we write the null hypothesis as $H_{0}: \pi_{i j}=\pi_{i .} \pi_{. j}$, all $i, j$. The alternative is $H_{1}: H_{0}$ is not true.

In statistical inference, the likelihood ratio test is shown to give approximately the $\chi^{2}$ test statistic

$$
X^{2}=\sum_{i j} \frac{\left(y_{i j}-n \hat{\pi}_{i .} \hat{\pi}_{. j}\right)^{2}}{n \hat{\pi}_{i .} \hat{\pi}_{. j}}=\sum_{i j} \frac{\left(O_{i j}-E_{i j}\right)^{2}}{E_{i j}}
$$

where $\hat{\pi}_{i .}=\frac{y_{i .}}{n}, \hat{\pi}_{. j}=\frac{y_{. j}}{n}, O_{i j}=y_{i j}$ is observed frequency and $E_{i j}=n \hat{\pi}_{i .} \hat{\pi}_{. j}=\frac{y_{i .} y_{. j}}{n}, i=1, \cdots, I, j=1, \cdots, J$. Under $H_{0}$ the distribution of $X^{2}$ is approximately $\chi^{2}$ with $(I-1)(J-1)$ degrees of freedom.

A Poisson model can be used to analyze contingency table data and test association between row and column classifications. In this model; we would fit a Poisson generalized linear model (GLM) even though the data is multinomial. Morever, the justification of this idea is given by the well-known result in (1).

$$
\begin{gathered}
Y_{i j}=\mu_{i j}+\varepsilon_{i j} \sim \operatorname{Pois}\left(\mu_{i j}\right) \text { independent } \\
\log \left(\mu_{i j}\right)=\log \left(n \pi_{i j}\right)=\mu+\alpha_{i}+\beta_{j}+\gamma_{i j}, i=1, \cdots, I, \quad j=1, \cdots, J .
\end{gathered}
$$

Under the Poisson model, the sum $Y_{. .}=Y_{11}+\cdots+Y_{I J} \sim$ Pois $\left(\mu_{. .}\right)$, where $\mu_{. .}=\mu_{11}+\cdots+\mu_{I J}=$ $n\left(\pi_{11}+\cdots+\pi_{I J}\right)=n$. The conditional distribution of $\left\{y_{i j}\right\}$ given $Y_{. .}=n$ is multinomial:

$$
\begin{aligned}
P\left(Y_{11}=y_{11}, \cdots, Y_{I J}=y_{I J} \mid Y_{. .}=n\right) & =\frac{P\left(Y_{11}=y_{11}, \cdots, Y_{I J}=y_{I J}\right)}{P\left(Y_{. .}=n\right)} \\
& =\prod_{i j} \frac{\left(n \pi_{i j}\right)^{y_{i j}} e^{-n \pi_{i j}}}{y_{i j} !} / \frac{n^{n} e^{-n}}{n !} \\
& =\frac{n !}{n^{n} e^{-n}} \prod_{i j} \frac{n^{y_{i j}} \pi_{i j}^{y_{i j}} e^{-n \pi_{i j}}}{y_{i j} !} \\
& =\frac{n ! n^{\sum_{i j} y_{i j}}}{n^{n} e^{-n}} \prod_{i j} \frac{\pi_{i j}^{y_{i j}} e^{-n \sum_{i j} \pi_{i j}}}{y_{i j} !} \\
& =\frac{n ! n^{n} e^{-n}}{n^{n} e^{-n}} \prod_{i j} \frac{\pi_{i j}^{y_{i j}}}{y_{i j} !} \\
& =\frac{n !}{\prod_{i j} y_{i j} !} \prod_{i j} \pi_{i j}^{y_{i j}}
\end{aligned}
$$

The interaction term $\gamma_{i j}$ can be interpreted as a log odds ratio, because

$$
\begin{aligned}
\gamma_{i j} & =\left(\mu+\alpha_{i}+\beta_{j}+\gamma_{i j}\right)-\left(\mu+\alpha_{i}\right)-\left(\mu+\beta_{j}\right)+\mu \\
& =\log \left(\mu_{i j}\right)-\log \left(\mu_{i 1}\right)-\log \left(\mu_{1 j}\right)+\log \left(\mu_{11}\right) \\
& =\log \left(\frac{\mu_{i j}}{\mu_{i 1}} / \frac{\mu_{1 j}}{\mu_{11}}\right)
\end{aligned}
$$




$$
=\log \left(\frac{\pi_{i j}}{\pi_{i 1}} / \frac{\pi_{1 j}}{\pi_{11}}\right) .
$$

Data

The data for this study was obtained from the Nigeria Demographic and Health Survey, 2013, which was compiled by the National Population Commission (NPC) Nigeria and ICF International in 2014. It comprises of the percentage of ever-married women age 15-49 who have ever experienced emotional, physical, or sexual violence committed by their husband/partner, by husband's characteristics and women's empowerment indicators, Nigeria 2013.

\section{RESULTS AND DISCUSSIONS}

The data in the Nigeria Demographic and Health Survey, 2013 [7] report have been Analyzed using $\mathrm{R}$ programme for windows. To maximize cell space in Table 2 and 3 we denote physical violence and sexual violence by $\mathrm{PV}$ and SV, respectively.

Table 2. Fitted Additive Model (Reduced Model) with Poisson Error Distribution

\begin{tabular}{|l|c|c|c|c|}
\hline \multicolumn{1}{|c|}{ Coefficients } & Estimate & Std. Error & Z-value & P-value \\
\hline Intercept & 7.94451 & 0.01488 & 533.835 & $2.0 \times 10^{-16}$ \\
\hline Wife is 1-4 yrs younger & -0.35951 & 0.02004 & -17.943 & $2.0 \times 10^{-16}$ \\
\hline Wife is 10+ yrs younger & -0.64169 & 0.02187 & -29.335 & $2.0 \times 10^{-16}$ \\
\hline Wife is 5-9 yrs younger & -0.46146 & 0.02066 & -22.337 & $2.0 \times 10^{-16}$ \\
\hline Wife is same age & -0.68657 & 0.02220 & -30.925 & $2.0 \times 10^{-16}$ \\
\hline PV & -0.14399 & 0.01508 & -9.5460 & $2.0 \times 10^{-16}$ \\
\hline SV & -1.26231 & 0.02188 & -57.693 & $2.0 \times 10^{-16}$ \\
\hline
\end{tabular}

Null deviance: 6140.17 on 14 degrees of freedom Residual deviance: 335.41 on 8 degrees of freedom AIC: 482.27

Table 3. Fitted Multiplicative Model (Full Model) with Poisson Error Distribution

\begin{tabular}{|c|c|c|c|c|}
\hline Coefficients & Estimate & Std. Error & Z-value & P-value \\
\hline Intercept & 7.77486 & 0.02050 & 379.298 & $2.0 \times 10^{-16}$ \\
\hline Wife is $1-4$ yrs younger & -0.13955 & 0.03005 & -4.643 & $3.43 \times 10^{-6}$ \\
\hline Wife is $10+$ yrs younger & -0.35428 & 0.03192 & -11.098 & $2.0 \times 10^{-16}$ \\
\hline Wife is same age & -0.49554 & 0.03331 & -14.875 & $2.0 \times 10^{-16}$ \\
\hline PV & 0.08456 & 0.02839 & 2.978 & $2.90 \times 10^{-3}$ \\
\hline Wife is $10+$ yrs younger : PV & -0.50207 & 0.04811 & -10.437 & $2.0 \times 10^{-16}$ \\
\hline Wife is $5-9$ yrs younger : PV & -0.34115 & 0.04486 & -7.604 & $2.87 \times 10^{-14}$ \\
\hline Wife is same age : PV & -0.16345 & 0.04735 & -3.452 & $5.57 \times 10^{-4}$ \\
\hline Wife is $1-4$ yrs younger : SV & -0.72315 & 0.06320 & -11.442 & $2.0 \times 10^{-16}$ \\
\hline Wife is $10+$ yrs younger : SV & -0.59940 & 0.06571 & -9.122 & $2.0 \times 10^{-16}$ \\
\hline
\end{tabular}

Null deviance: 6140.20 on 14 degrees of freedom

Residual deviance: $2.4158 \times 10^{-13}$ on 0 degrees of freedom

AIC: 162.86

The algebraic form of the fitted multiplicative model in Table 3 is given by

$y_{i j}=\mu_{i j}+\varepsilon_{i j} \sim \operatorname{Pois}\left(\mu_{i j}\right)$ independent

$\log \left(\mu_{i j}\right)=\mu+\alpha_{i}+\beta_{j}+\gamma_{i j}$

where 
$y_{i j}=$ no. of wives that fall under spousal age difference $i$ and violence against wife $j$;

$\mu_{i j}=$ common term for all $i, j$;

$\alpha_{i}=$ extra due to spousal age difference $i\left(\alpha_{1}=0\right)$;

$\beta_{j}=$ extra due to violence against wife $j\left(\beta_{1}=0\right)$, and

$\gamma_{i j}=$ extra due to the combination of spousal age difference $i$ and violence against wife $j\left(\gamma_{1 j}=\gamma_{i 1}=0 \forall i, j\right)$.

Also, the algebraic form of the fitted additive model in Table 2 is exactly (2) with the interaction term $\gamma_{i j}=0$ in (3).

Two models: additive and multiplicative has been fitted to the data in [7] and the results obtained from the additive model gives a deviance statistic of 335.41 on $8 d f$. This statistic is higher than the $5 \%$ Chi-square upper tail critical value at $8 d f(15.50731)$. However, this implies that there is significant evidence at $5 \%$ for association (interaction) between spousal age difference and violence against wife in Nigeria. The very small $p$-values of the interaction terms in Table 3 are also a clear indication of possible association between spousal age difference and violence against wife in Nigeria. Considering the odd ratios, for example, the odd ratio of experiencing physical violence $(j=2)$ against emotional violence $(j=1)$ for a wife who is same age as her husband $(i=2)$ compared with a wife who is older than her husband $(i=1)$ is $\left(\mu_{22} / \mu_{21}\right) /\left(\mu_{12} / \mu_{11}\right)=e^{-0.16345}=0.849209<1$. This implies that the odd of experiencing physical violence for a wife who is same age as her husband is about 0.849209 less (against emotional violence) than a wife who is older than her husband. Again, it is an indication of association. The reduced model is therefore dropped in favour of the full model for further analysis such as the computation of various related probabilities of a wife in certain age category experiencing one of the following violence: emotional, physical, or sexual from her husband in Nigeria and the result is shown in Table 4.

Table 4. Probabilities of Husbands perpetrating Violence against Wives in Nigeria

\begin{tabular}{|l|c|c|c|}
\hline Spousal age difference & Emotional violence & Physical violence & Sexual violence \\
\hline Wife is older & 0.1169538 & 0.03509958 & 0.002889718 \\
\hline Wife is same age & 0.0236906 & 0.03509958 & 0.002889718 \\
\hline Wife is 1-4 yrs younger & 0.0372480 & 0.03594856 & 0.001896726 \\
\hline Wife is 5-9 yrs younger & 0.0343274 & 0.01449058 & 0.001640103 \\
\hline Wife is 10+ yrs younger & 0.0272766 & 0.01352458 & 0.001227291 \\
\hline
\end{tabular}

Wives who are older than their husbands and wives whose age are the same with their husband are more likely to experience sexual violence but wives who are older than their husbands are more likely to experience emotional violence. Wives who are 1-4 years younger than their husbands are more likely to experience physical violence followed by wives who are older than their husbands and same age with their husbands with equal probability; while wives 5-9 years and 10+ years younger than their husbands are less likely to experience any of the violence.

\section{CONCLUSION}

Generalized linear modelling has been used to analyze the categorical data of spousal age difference and violence against wife in Nigeria. Results obtained show that the act of violence by the husband against wife is largely stirred by the age difference between the spouses. Interestingly, this paper found among others that wives whose husbands are 5 years and over older are less likely to experience emotional, physical, or sexual violence. This paper highlights the importance of age difference and its contribution to violence against wives by their husbands/partners and serves an instrument of guide to those who are in the corridor of making their choice of a marriage partner. This study will help in curbing the heightening frequency of reported cases of violence against wives in Nigeria.

\section{REFERENCES}

Essel P. I (2013). Effects of violence against Women in Ghana. https://www.womankind.org.uk/ blog/detail/our-blog/2013/03/18/effects-of-violence-against-women-in-ghana. 


\section{Anthony C. Akpanta et al.}

Bowman, C. (2000). Mar David Peterson del, What Trouble I Have Seen: A History of Violence Against Wives, Cambridge: Harvard University Press, 1996. Pp. 244 ix. \$39.95 cloth; 16.95 paper (ISBN 0-674-95076-3; 0-674-95078-X). Law and History Review, 18(1), 234-236. doi: $10.2307 / 744365$.

Amoakohene, M. I. (2004). Violence against women in Ghana: a look at women's perceptions and review of policy and social responses. Social Science \& Medicine, 59(11), 2373-2385.

Ellsberg, M., Heise, L., Pena, R., Agurto, S., \& Winkvist, A. (2001). Researching domestic violence against women: methodological and ethical considerations. Studies in family planning, 32(1), $1-16$.

Krantz, G., \& Garcia-Moreno, C. (2005). Violence against women. Journal of Epidemiology \& Community Health, 59(10), 818-821.

Jensen, R., \& Thornton, R. (2003). Early female marriage in the developing world. Gender \& Development, 11(2), 9-19. http://www.jstor.org/stable/4030636.

National Population Commission (NPC) Nigeria and ICF International. 2014. Nigeria Demographic and Health Survey, 2013. Abuja, Nigeria and Rockville, Maryland, USA. NPC and ICF International, pp.318. https://dhsprogram.com/pubs/pdf/FR293/FR293.pdf.

Dobson, A. J. (1990) An Introduction to Generalized Linear Models. London: Chapman and Hall.

McCullagh P. and Nelder, J. A. (1989) Generalized Linear Models. London: Chapman and Hall. 